\title{
Research on Influencing Factors for Information Service Quality of Online Learning Platform under New Media Environment
}

\author{
Qiong Li \\ Department of Management, \\ Xuzhou University of Technology \\ Xuzhou, China
}

\author{
Lei Wang \\ Information Center \\ Yi-Shu-Si River Basin Administrator Bureau \\ Xuzhou, China
}

\begin{abstract}
Under the new media environment, Online Learning Platform have emerged in succession. This paper chooses Online Learning Platform as the research object, the influencing factors model for information service quality of online learning platform under new media environment is constructed. Relevant data are collected through questionnaires, and the model is revised by factor analysis. On this basis, this paper puts forward relevant strategies to improve the quality of information service and the information service capability of Online Learning Platform.
\end{abstract}

Keywords-academic new media; online learning platform; information service quality; influencing factor

\section{INTRODUCTION}

In the rapid development of the Internet, new media, a digital media form, has flourished. More and more new media technologies and tools are constantly infiltrating into the education industry. This innovative integration undoubtedly provides a new way of thinking for the development of traditional education. With the new media technology entering the classroom, its advantages gradually emerged, and an online education platform different from the traditional education mechanism and system was established. The content and form of modern teaching quietly changed.

The Online Learning Platform under the new media technology provides a new online learning mode, breaks the traditional classroom mode, and provides students with more abundant teaching resources and more flexible teaching means. Students are no longer limited by the fixed time and place of traditional teaching. They can learn by PC or mobile terminal, which improves students' interest and efficiency in learning, and also improves the quality of teachers' teaching service. Online Learning Platform has become an indispensable teaching aids.

\section{INFORMATION SERVICE OF ONLINE LEARNING PLATFORM AND ITS QUALITY}

Information service process of Online Learning Platform is based on the needs of users, using the Online Learning Platform platform, using different service modes or methods to provide a series of collated and processed academic information service content to the target group, in order to achieve the dissemination and exchange of academic information.

Information service is a kind of social service with information as its content. Its object of service is the social subject with objective requirements for service. ${ }^{[1]}$ Online Learning Platform information service is a service activity that provides various academic information services to users. These academic information services include not only the various services provided to users, but also the information service products presented eventually. Therefore, this paper defines information service quality of Online Learning Platform as the quality of the service and information service products finally formed. It reflects the income of target users from information service providers, and whether the information services obtained by information service users meet their own needs.

As the effective operation of Online Learning Platform can not be separated from the participation of users, the quality of information service of Online Learning Platform is affected by the level of information service capability, and the subjective feelings of users will have a great impact on the information service quality of Online Learning Platform. Therefore, it is necessary to measure the information service quality of online learning platform based on users' subjective feelings.

\section{CONSTRUCTING HYPOTHESIS MODEL OF INFLUENCING FACTORS ON INFORMATION SERVICE QUALITY OF ONLINE LEARNING PLATFORM}

On the basis of the relevant research results on the influencing factors of the information service quality of academic new media ${ }^{[3]}$, this paper combines the characteristics of Online Learning Platform, and analyzes information service quality of Online Learning Platform from four aspects of "information resources content", "system platform", "user characteristics" and "service process". A total of 29 factors were identified. The hypothesis model of influencing factors of information service quality of Online Learning Platform is shown in Table 1. 
TABLE I HYPOTHESIS MODEL OF INFLUENCING FACTORS OF INFORMATION SERVICE QUALITY OF ONLINE LEARNING PLATFORM

\begin{tabular}{|c|c|c|}
\hline NO. & dimension & influence factor \\
\hline 1 & Content of Information Resources & $\begin{array}{l}\text { Truthfulness and reliability of content } \\
\text { Content integrity } \\
\text { Content richness } \\
\text { Content practicability } \\
\text { Content accessibility } \\
\text { Timeliness of content updating } \\
\text { Interesting content }\end{array}$ \\
\hline 2 & system platform & $\begin{array}{l}\text { Page design friendliness } \\
\text { Beauty of Page Design } \\
\text { Navigation clarity } \\
\text { Navigation ease of use } \\
\text { Operation stability of platform } \\
\text { Platform operation fluency } \\
\text { Technical Support of Platform } \\
\text { Platform Interaction }\end{array}$ \\
\hline 3 & User characteristics & $\begin{array}{l}\text { User expectations } \\
\text { User Knowledge Background } \\
\text { User Information Literacy } \\
\text { User Habitual Preferences } \\
\text { User's Willingness to Use } \\
\text { User Satisfaction } \\
\text { User Perception }\end{array}$ \\
\hline 4 & Service process & $\begin{array}{l}\text { Completeness of Service Function } \\
\text { Service Effectiveness } \\
\text { Personalization of Service } \\
\text { Service costs } \\
\text { Service Attitude } \\
\text { service efficiency } \\
\text { Quality and Ability of Service Personnel }\end{array}$ \\
\hline
\end{tabular}

\section{QUESTIONNAIRE SURVEY BASED ON HYPOTHESIS MODEL}

This paper collects relevant data of information service quality of Online Learning Platform by means of questionnaire survey. The content of the questionnaire is designed around 29 factors listed in the hypothesis model of influencing factors of information service quality of Online Learning Platform. Questionnaires were distributed and collected through various network platforms such as micro-blog and post bar... 214 questionnaires were eventually recovered. After eliminating the invalid questionnaires such as too short response time and all the same options, 182 valid questionnaires were finally obtained, which accorded with the expected number of samples.

In this survey, the proportion of women is significantly higher than that of men in terms of gender, with $26.92 \%$ and $73.08 \%$ of the respondents. The age of the user group is generally between 18 and 30 years old, accounting for $92.86 \%$.In terms of education level, undergraduates ranked first, with $96.15 \%$ of the students having undergraduate or higher education experience. In terms of occupation, the majority of students are in school, up to $84.62 \%$.

The Cronbach Alpha coefficient of 29 items in the questionnaire is $0.940>0.9$. The test results show that the reliability of the questionnaire is very high and the internal consistency of the questionnaire is very good. Both KMO and Bartlett's chi-square values show that the design of the questionnaire is reasonable.

\section{MODEL REVISION}

Based on the above reliability and validity tests, we know that the reliability and validity of the questionnaire are very good, which meets the factor analysis conditions. Next, SPSS22.0 software is used to select the maximum variance method and eliminate the influence factors whose factor load coefficient is less than 0.4. After deleting the options several times, the KMO values are up to the standard and the corresponding relationship between the observed variables and the dimension is consistent. The presupposed 29 influencing factors with 4 dimensions turned into 20 influencing factors with 5 dimensions after rotation. And the variables contained in each dimension are different from the original hypothetical model. Therefore, it is necessary to revise the original hypothesis model and rename the five dimensions at the same time.

Based on the above results, the revised model of influencing factors on information service of Online Learning Platform is obtained. It is shown in Table 2. 
TABLE II. REVISION MOdEL OF INFLUENCING FACtors ON INFORMATION SERVICE QUALITY OF ONLINE LEARNING PLATFORM

\begin{tabular}{|c|l|l|}
\hline NO. & \multicolumn{1}{|c|}{ dimension } & \multicolumn{1}{|c|}{ influence factor } \\
\hline 1 & Information Resources and Navigation Functions & $\begin{array}{l}\text { Truthfulness and reliability of content } \\
\text { Content integrity } \\
\text { Content richness } \\
\text { Content practicability } \\
\text { Timeliness of content updating Navigation clarity } \\
\text { Navigation ease of use }\end{array}$ \\
\hline 2 & User Internal Characteristics and Personalized Services & $\begin{array}{l}\text { User Knowledge Background } \\
\text { User Information Literacy } \\
\text { User expectations } \\
\text { Personalization of Service }\end{array}$ \\
\hline 3 & User External Characteristics & $\begin{array}{l}\text { User's Willingness to Use } \\
\text { User Satisfaction } \\
\text { User Perception }\end{array}$ \\
\hline 4 & Page Design and Platform Interaction & $\begin{array}{l}\text { Page design friendliness } \\
\text { Beauty of Page Design } \\
\text { Platform Interaction }\end{array}$ \\
\hline 5 & Platform Technical Services & $\begin{array}{l}\text { Operation stability of platform } \\
\text { Platform operation fluency } \\
\text { Technical Support of Platform }\end{array}$ \\
\hline
\end{tabular}

The reliability and validity of the revised five dimensions are tested. The results show that the model of influencing factors of information service quality of the revised online learning platform is reasonable.

\section{STRATEGIES TO IMPROVE THE INFORMATION SERVICES QUALITY OF ONLINE LEARNING PLATFORM}

Through the above analysis, we can improve the information service quality of Online Learning Platform from the following five aspects:

\section{A. Enhancing the practicability of media resources}

Rich academic resources are the basis of attracting users to use Online Learning Platform. Under the background of the strong utilitarianism of network learning, users are paying more and more attention to the practicability of course content. Therefore, Online Learning Platform should pay attention to enhancing the practicability of the course content, and ensure that users can apply the knowledge to practice in time after completing the course learning, so as to enhance the enthusiasm of users in learning. To meet this user demand, each platform can first screen out the resources with strong practicability of user evaluation, and classify them according to the type of resources, and then set up a topic of practical resources, so that users can easily retrieve and learn.

\section{B. Optimizing Navigation Function of User Platform for Online Learning Platform}

Navigation function is a direct way for users to obtain course content, and plays a guiding role in the use of users. Navigation clarity and ease of use are very important.

The main purpose of online learning platform is to provide users with a variety of course resources for learning. Users need to register, watch course ware.... These require the platform to continuously improve the platform navigation function based on user perception, realize the effective use of platform resources, and bring convenient services to users. In addition to highlighting the navigation functions commonly used by users, the platform interface should conform to the user's habits of using and browsing, enhance the structure and hierarchy of the platform, set up navigation reasonably, and facilitate users to quickly learn platform content.

\section{Providing personalized services for users}

Users are the direct experiencers of Online Learning Platform, so it is very important to meet users' personalized needs. By satisfying the personalized needs of users, users can get more satisfactory services, thereby improving the quality of information services on the platform.

By mining and analyzing learner's behavior data, matching the corresponding learning activities for different learning behaviors of users, recommending personalized learning paths, and pushing appropriate curriculum resources with the help of information agent. In this way, by locating the individual needs of users, personalized services are provided to users with the help of big data. Thus learners' individualized learning is realized and their learning is improved efficiency.

\section{Promoting the Interaction of Online Learning Platform}

The interaction on Online Learning Platform is not only reflected between learners and learners, but also between learners and teachers. Ensuring the effective implementation of the two interactive modes can improve the information service quality of the platform. ${ }^{[2]}$

\section{1) Organizing online and offline interaction among} learners

According to the survey, the interaction between learners and learners on the existing Online Learning Platform mostly depends on online discussion forum. Since online learners usually come from different regions, they can organize "online learner alliances ", organize regular learning and communication activities, discuss and exchange curriculum issues together, enhance friendship and promote common growth. "Off-line student-friend exchange" can be set up according to schools or regions to urge each other to punch in. This way can strengthen the friendship between alumni, make learners have a sense of belonging, and improve the completion rate of the course. 
2) Increase the way of interaction between teachers and students

In addition to participating in the discussion in the course forum on the platform, teachers can also use various existing social media, such as QQ, Weixin, Weibo and other social media, to interact with students in real time. In the case of a large number of interactions, teachers can arrange several assistants to ensure that there are teachers or assistants during the course.

\section{E. Technical Guarantee}

Ensuring the normal operation of the system platform can ensure the use of the platform interface and the service process, and provide users with high-quality service experience.

\section{CONCLUSION}

In summary, the factors affecting the information service quality of Online Learning Platform can be summarized as curriculum content, platform navigation function, user personalized service, platform interaction and platform technical support. On this basis, Online Learning Platform could enhance the practicability of media resources, optimize the navigation function of Online Learning Platform user platform, provide personalized services for users, and promote the interaction of Online Learning Platform ... so as to improve the information service quality of Online Learning Platform.

\section{REFERENCES}

[1] Hu Changping. Information Services and Users [M]. Wuhan: Wuhan University Press, 2015. (In Chinese)

[2] Osatuyi B,James K.Twittermania: Understanding how social media technologies impact engagement and academic performance of a new generation of learners[J]. Communications of the Association for Information Systems,2016,39(1):509-528.

[3] Ma Xinchen. Research on Influencing Factors of Information Quality of New Media [D]. Zhenjiang: Jiangsu University, 2017. (In Chinese)

[4] Chen Weidong, Wang Ping, Wang Yicheng. Research on the elements and internal mechanism of user information encounter under the new academic media environment [J]. Information theory and practice, 2018 (02): 28-33. (In Chinese)

[5] Li Yujia. Research on Information Service Model and Service Quality Evaluation of Academic New Media [D]. Changchun: Jilin University, 2017. (In Chinese)

[6] Yao Ning, Xia Yongmei, Zhang Ying. Knowledge Aggregation and Innovation Service of Academic New Media Driven by Data [J]. Journal of Library Science, 2018 (08): 91-94. (In Chinese) 